\title{
Study on Weighting Method of Functions and Performance Indicator
}

\section{System of IETM Authoring System}

\author{
Xu Zongchang ${ }^{1, a, *}$, Hu Chunyang ${ }^{1, a}$, Sun Hanbing ${ }^{1, a}$ \\ ${ }^{1}$ Dept of Technical Support Engineering, Academy of Armored Force Engineering, Beijing 100072, \\ China \\ ahuchunyang21@163.com
}

Keywords: IETM authoring system, functions and performance, indicator system, weight Abstract. IETM authoring system is the important instrument to make IETM. Studying its indicator system helps choosing them. This paper introduces overviews of the indication system, then combining several weighting methods, achieves quantitating weights of functions and performance indicators of IETM authoring system by using AHP.

\section{Introduction}

Popularizing IETM has been becoming common view in related area recently. But as important instrument to make IETM, there is lacking studies on evaluating functions and performance of IETM authoring system. It's a problem needed to solve that how to choose a better authoring system. The first step to evaluate functions and performance of authoring system is to study the weighting method of indicator system. After analyzing features of indicator system and many weighting methods, this paper uses AHP to quantitate weights of indicators system.

\section{Functions and Performance Indicator System of IETM Authoring System}

As shown in the table 1.

Table 1 Functions and Performance Indicator System of IETM Authoring System

\begin{tabular}{|l|l|l|}
\hline \multicolumn{1}{|c|}{ primary indicators } & secondary indicators & \multicolumn{1}{c|}{ bottom indicators } \\
\hline \multirow{5}{*}{ creating and editing $C$} & text editing $C_{1}$ & $\begin{array}{l}\text { structure content editing } C_{11} \\
\text { XML editing } C_{12} \\
\text { data transferring } C_{13} \\
\text { document conversion } C_{14} \\
\text { spare parts catalog editing } C_{15}\end{array}$ \\
\cline { 2 - 3 } & multimedia handling $C_{2}$ & $\begin{array}{l}\text { image handling } C_{21} \\
\text { graph handling } C_{22} \\
\text { other multimedia handling } C_{23}\end{array}$ \\
\cline { 2 - 3 } & processing manner $C_{3}$ & $\begin{array}{l}\text { flow information organizing } C_{31} \\
\text { interactive windows editing } C_{32} \\
\text { distributed edition } C_{33}\end{array}$ \\
\hline \multirow{5}{*}{$\begin{array}{l}\text { information managing } \\
G\end{array}$} & data managing $G_{1}$ & $\begin{array}{l}\text { basic data configuring } G_{11} \\
\text { data configuration flexibility } G_{12} \\
\text { data module managing } G_{13} \\
\text { business rule exchange managing } G_{14} \\
\text { publication module managing } G_{15} \\
\text { multimedia information managing } G_{16} \\
\text { annotation and experience managing } G_{17} \\
\text { data retrieving } G_{18}\end{array}$ \\
\hline & &
\end{tabular}




\begin{tabular}{|l|l|l|}
\hline \multicolumn{1}{|c|}{ primary indicators } & \multicolumn{1}{|c|}{ secondary indicators } & \multicolumn{1}{c|}{ bottom indicators } \\
\hline $\begin{array}{l}\text { information managing } \\
G\end{array}$ & procedure managing $G_{2}$ & $\begin{array}{l}\text { item managing } G_{21} \\
\text { data management list managing } G_{22} \\
\text { content package(based on } S C O R M) \text { managing } G_{23} \\
\text { multimedia operating } G_{24} \\
\text { work flow managing } G_{25} \\
\text { applicability examining } G_{26} \\
\text { information verifying } G_{27}\end{array}$ \\
\hline displaying \\
publishing $F$ & - & $\begin{array}{l}\text { flexibility of display interface format } F_{01} \\
\text { display engine processing effect } F_{02} \\
\text { extract data fast to publish } F_{03} \\
\text { browser display engine customizability } F_{04} \\
\text { publication form } F_{05} \\
\text { flexibility of production navigation and browse } F_{06} \\
\text { operation procedure viewing } F_{07} \\
\text { maintenance package automatic generation } F_{08}\end{array}$ \\
\hline system performance $X$ & - & $\begin{array}{l}\text { dependability } X_{01}, \text { expandability } X_{02} \text {, timeliness } X_{03} \\
\text { ease of use } X_{04}, \text { commonality } X_{05} \text {, security } X_{06} \\
\text { compatibility } X_{07}, \text { operation environment } X_{08}\end{array}$ \\
\hline
\end{tabular}

This indicator system that reflects authoring system roundly and accurately is generated by inductive method, analytical method, combined technique and features grouping method, according to analyzing IETM standard, making process, technical architecture and function compositions, and concluding requirements that authoring system have to meet from 4 aspects, creating\& editing, information managing, displaying\& publishing and system performance.

\section{Weighting Method}

There are many weighting methods usually divided into: subjective methods e.g. AHP and DELPHI etc. objective methods e.g. entropy weight method and principal component analysis etc. and combination method. Because the evaluation indicator system mainly consists of qualitative indicators and these indicators are difficult to quantify, it's suited to apply specialist experience. There are common weighting methods below.

\subsection{Direct Weighting Method}

This method means using experience or intuition to quantify the importance of each indicator directly, generally using proportion to allocate weight. For example, some indicators' weights specific value is, then calculating relative numbers of this proportion and resulting in each indicator's weights. Direct weighting method is basic, easy and convenient, but is the subjective that is effected badly by persons. In order to weaken subjective randomness, it is better to use this method combining expert group method.

\subsection{Expert Group Weighting Method}

Because of everyone's subjective randomness, we can synthesize some experts' opinions, including feedback and without feedback, shown in the figure 1. The method without feedback means that evaluation personnel directly calculate weights by integrating various information from expert group. The other method has feedback mechanism that evaluation personnel obtain more reasonable weight allocation by communicating with expert group many times.
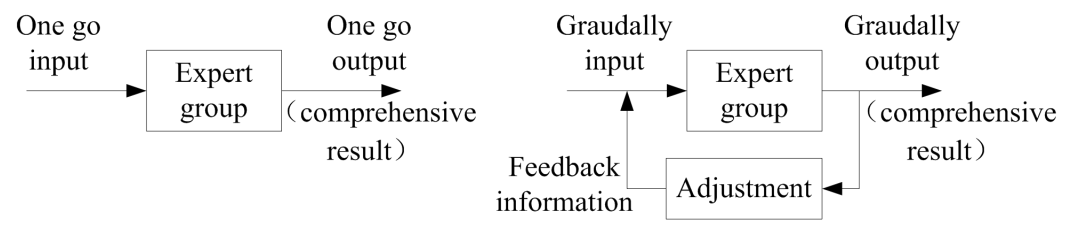

(A) no feedback system

(B) feedback system

Figure 1 Expert Group Weighting Method 


\subsection{AHP}

AHP is an extensive-using and basic weighting method, through building hierarchical structure, analyzing relative importance by comparing one with one gradually.

First, build hierarchical structure.

Second, form matrix for comparison between every two indicators, and, is the importance that compared ith element with jth element according to the same norm and refer to table 2.

Table 2 importance between two elements

\begin{tabular}{|c|c|}
\hline value of $a$ & meaning \\
\hline $9 / 9=1$ & indicator $i$ is as important as indicator $j$ \\
\hline $9 / 7=1.286$ & indicator $i$ is slightly more important than indicator $j$ \\
\hline $9 / 5=1.8$ & indicator $i$ is obviously more important than indicator $j$ \\
\hline $9 / 3=3$ & indicator $i$ is mightily more important than indicator $j$ \\
\hline $9 / 1=9$ & indicator $i$ is extremely more important than indicator $j$ \\
\hline $9 / 8=1.125$ & \\
$9 / 6=1.5$ & importance between two contiguous levels above \\
$9 / 4=2.25$ & \\
$9 / 2=4.5$ & \\
\hline reciprocal of number above & compare indicator $j$ with indicator $i$ \\
\hline
\end{tabular}

Third, calculate relative weight.

1. Calculate $k$ order average number column by column, $(j=1,2, \ldots . ., \mathrm{n})$, commonly the value of $\mathrm{k}$ is integer nearby zero.

2. Make matrix above normalize to become , and 。

3. Sum row elements of matrix $B$ and uniformization, , so weights are concluded by vector .

Fourth, check consistency. The formula is below:

is the ith element, RI could be found by table.

If , the check is passed, if not, it should be checked again until it is passed by adjusting matrix for comparison between every two indicators.

It is extremely suitable to apply AHP and expert opinions to the functions and performance indicator system.

\section{Applying AHP to Functions and Performance Indicator Weights of IETM Authoring System}

Hierarchical structure is shown in the table 1. Letting $k=2$ would make result accurate and simplify calculation procedure. Take text editing for example, according to expert opinions, this paper get a judgment matrix :

Put into AHP calculation procedure results in weight vector $\mathrm{W}=(0.3593,0.2993,0.1085,0.1615,0.1014)$ and the greatest characteristic root $=5.048638$, then check consistency $\mathrm{CI}=0.012159, \mathrm{CR}=0.010857<0.1$, so the result pass the test. Using the same method could get other weight vectors of indicators and all functions and performance indicator weights of IETM authoring system which is shown in table 4.

Table 4 Functions and Performance Indicator Weights of IETM Authoring System 


\begin{tabular}{|c|c|c|c|c|c|c|c|}
\hline $\begin{array}{c}\text { primary } \\
\text { indicator }\end{array}$ & creating ar & editing & & $\begin{array}{l}\text { information } \\
\text { managing }\end{array}$ & .361 & $\begin{array}{l}\text { displaying } \\
\text { and } \\
\text { publishing }\end{array}$ & $\begin{array}{l}\text { system } \\
\text { performance }\end{array}$ \\
\hline $\begin{array}{l}\text { secondary } \\
\text { indicator }\end{array}$ & $\begin{array}{l}\text { text } \\
\text { editing } \\
0.4699\end{array}$ & $\begin{array}{l}\text { multimedia } \\
\text { handling } \\
0.3333\end{array}$ & $\begin{array}{l}\text { processin } \\
\mathrm{g} \text { manner } \\
0.1968\end{array}$ & $\begin{array}{l}\text { data } \\
\text { managing } \\
0.5\end{array}$ & $\begin{array}{l}\text { procedure } \\
\text { managing } \\
0.5\end{array}$ & - & - \\
\hline $\begin{array}{l}\text { bottom } \\
\text { indicator }\end{array}$ & $\begin{array}{ll}C_{11} & 0.3293 \\
C_{12} & 0.2993 \\
C_{13} & 0.1085 \\
C_{14} & 0.1615 \\
C_{15} & 0.1014\end{array}$ & $\begin{array}{ll}C_{21} & 0.6065 \\
C_{22} & 0.2346 \\
C_{23} & 0.1588\end{array}$ & $\begin{array}{ll}C_{31} & 0.3438 \\
C_{32} & 0.2760 \\
C_{33} & 0.2348\end{array}$ & $\begin{array}{ll}G_{11} & 0.1727 \\
G_{12} & 0.0967 \\
G_{13} & 0.2109 \\
G_{14} & 0.1482 \\
G_{15} & 0.1316 \\
G_{16} & 0.1043 \\
G_{17} & 0.0651 \\
G_{18} & 0.0704\end{array}$ & $\begin{array}{ll}G_{21} & 0.2611 \\
G_{22} & 0.1631 \\
G_{23} & 0.0944 \\
G_{24} & 0.1186 \\
G_{25} & 0.1536 \\
G_{26} & 0.1102 \\
G_{27} & 0.0990\end{array}$ & $\begin{array}{ll}F_{01} & 0.1027 \\
F_{02} & 0.0831 \\
F_{03} & 0.1683 \\
F_{04} & 0.0610 \\
F_{05} & 0.1638 \\
F_{06} & 0.1297 \\
F_{07} & 0.0733 \\
F_{08} & 0.1170\end{array}$ & $\begin{array}{ll}X_{01} & 0.1683 \\
X_{02} & 0.0659 \\
X_{03} & 0.1024 \\
X_{04} & 0.0570 \\
X_{05} & 0.3343 \\
X_{06} & 0.0640 \\
X_{07} & 0.0968 \\
X_{08} & 0.0417\end{array}$ \\
\hline
\end{tabular}

\section{Conclusion}

Basing on analyzing features of functions and performance indicator system of IETM authoring system, this paper studies direct weighting method, expert group weighting method weighting method and AHP, then applies AHP to quantifies indicator system weights, obtain a set of weight distribution table which can guide choosing and developing IETM authoring system, having significant use value.

\section{Conference}

[1] Du Dong. Modern Comprehensive Evaluation Method and well-chosen case [M]. Tsinghua University Press, 2005

[2] Zhao Feng. The Evaluation Index System Research about the Competitiveness of the Software and Information Services Industry [D]. Dongbei University of Finance and Economics, 2010.

[3] Su Weihua. Study on Theory and Method of Multi-index Comprehensive Evaluation [D]. Xiamen University, 2004.

[4] Leng Bingbo, Zhou Hongjun, Wang Xueying. Study on ERP Supplier evaluation model based on AHP and Fuzzy Theory [J]. Journal of ShenYang Normal University Natural Science Edition, 2013, 01:100-104.

[5] Li Suicheng, Chen Jingdong. Studying on the Method of Appraising Qualitative Decision Indication System [J]. Systems Engineering-Theory \& practice, 2001, 21:22-28.

[6] Li Zongliang. Research on IETM System Technology Based on the S1000D Spcification[D]. Guangdong University of Technology, 2006. 